\title{
Хемотранскриптомный анализ
}

\section{молекулы этилметилгидроксипиридина сукцината в контексте постгеномной фармакологии}

\author{
Громова О.А. ${ }^{1,2}$, Торшин И.Ю. ${ }^{1,2}$, Сорокин А.И. ${ }^{2}$, Семенов В.А. ${ }^{3}$, Стаховская Л.В. ${ }^{4}$ \\ ${ }^{1}$ Институт фармакоинформатики Федерального исследовательского центра «Информатика и управление» \\ Российской академии наук, Москва; ${ }^{2}$ Центр хранения и анализа больших данных Национального центра цифровой \\ экономики ФГБОУ ВО «Московский государственный университет им. М.В. Ломоносова», Москва; \\ ${ }^{3}$ ФГБОУ ВО «Кемеровский государственный медицинский университет» Минздрава России, Кемерово; \\ ${ }^{4}$ НИИ иереброваскулярной патологии и инсульта при ФГБОУ ВО «Российский национальный \\ исследовательский медицинский университет им. Н.И. Пирогова» Минздрава России, Москва \\ ${ }^{1}$ Россия, 119333, Москва, ул. Вавилова, 44, корп. 2; ${ }^{2}$ Россия, 119234, Москва, Ленинские горы, 1; \\ ${ }^{3}$ Россия, 650056, Кемерово, ул. Ворошилова, 22а; ${ }^{4}$ Россия, 117997, Москва, ул. Островитянова, 1
}

В постгеномной фармакологии желательные и нежелательные эффекты лекарств рассматриваются по отношению к геному, транскриптому, протеому и реактому. Характеризация транскриптомной активности этилметилгидроксипиридина сукиината (ЭМПГС) ранее не проведилась.

Цель исследования - изучение дозозависимых эффектов воздействия ЭМПГС на транскрипцию 12700 аннотированных генов человека в клетках-предшественниках нейронов (клеточная линия NPC.TAK).

Материал и методы. Представлены результаты хемотранскриптомного анализа молекулы ЭМПГС с точки зрения влияния на транскрипцию генома человека в клетках линии NPC.TAК при инкубации клеток с ЭМГПС в течение 24 ч.

Результаты и обсуждение. Достоверные дозозависимые эффекты влияния ЭМГПС на транскрипцию (в среднем $\geqslant 10 \%$ изменения транскрипции на каждый 1 мкмоль/л ЭМПГС) были оценены для 2400 из 12700 аннотированных генов человека. ЭМПГС снижает транскрипцию групп генов, вовлеченных в деление клетки (226 генов), в процессы экспрессии генов (122 гена), а также в синтез, деградацию и секрецию белков (123 гена). ЭМПГС повышает транскрипцию генов, кодирующих белки, участвующие в нейротрансмиссии (103 гена) и в осуществлении нейропротекторных и нейротрофических эффектов (49 генов).

Заключение. Эффективность ЭМПГС может быть связана с его влиянием на транскрипцию генов, которые участвуют в нейротрансмиссии, в осуществлении нейропротекторных и нейротрофических эффектов.

Ключевые слова: хемотранскриптомика; этилметилгидроксипиридина сукцинат; интеллектуальный анализ данных; молекулярная фармакология; нейроны; сверхбольшие данные.

Контакты: Ольга Алексеевна Громова; ипеsco.gromova@gmail.com

Для ссылки: Громова ОА, Торшин ИЮ, Сорокин АИ и др. Хемотранскриптомный анализ молекулы этилметилгидроксипиридина сукцината в контексте постгеномной фармакологии. Неврология, нейропсихиатрия, психосоматика. 2020;12(5):130-137. DOI: 10.14412/2074-2711-2020-5-130-137

Chemotranscriptome analysis of the ethylmethylhydroxypyridine succinate molecule in the context of postgenomic pharmacology Gromova O.A. ${ }^{1,2}$, Torshin I. Yu. ${ }^{1,2}$, Sorokin A.I. ${ }^{2}$, Semenov V.A. ${ }^{3}$, Stakhovskaya L.V. ${ }^{4}$

${ }^{\prime}$ Institute of Pharmacoinformatics, Federal Research Center «Informatics and Management», Russian Academy of Sciences, Moscow; ${ }^{2}$ Center for Big Data Storage and Analysis, National Center for Digital Economy, M.V. Lomonosov Moscow State University, Moscow;

${ }^{3}$ Kemerovo State Medical University, Ministry of Health of Russia, Kemerovo; ${ }^{4}$ Research Institute of Cerebrovascular Pathology and Stroke, N.I. Pirogov Russian National Research Medical University, Ministry of Health of Russia, Moscow 144, Vavilov St., Build. 2, Moscow 119333, Russia; ${ }^{2}$ 1, Leninskie Gory, Moscow 119234, Russia; ${ }^{3} 22 a$, Voroshilov St., Kemerovo 650056, Russia; ${ }^{4}$ Ostrovityanov St., Moscow 117997, Russia

Postgenomic pharmacology deals with the desirable and undesirable effects of drugs in relation to the genome, transcriptome, proteome, and reactome. The transcriptomic activity of ethylmethylhydroxypyridine succinate (EMHPS) has not been previously characterized.

Objective: to investigate the dose-dependent effects of EMHPS on the transcription of 12,700 annotated human genes in the neural progenitor cells (NPC.TAK cell line).

Material and methods. The paper presents the results of chemotranscriptome analysis of the EMHPS molecule from the point of view of its impact on transcription of the human genome in the NPC.TAK line cells during 24-hour incubation of cells with EMHPS.

Results and discussion. The significant dose-dependent effects of EMHPS on transcription (on average, $\geqslant 10 \%$ transcription changes for each $1 \mu \mathrm{mol} / L$ of EMHPS) were evaluated for 2,400 of the 12,700 annotated human genes. EMHPS reduced the transcription of groups of the genes that were involved in cell division $(n=226)$, those in gene expression processes $(n=122)$, and those in protein synthesis, degradation, and secretion $(n=123)$. EMHPS increased the transcription of the genes encoding proteins involved in neurotransmission ( $n=103)$ and those in exerting neuroprotective and neurotrophic effects $(n=49)$. 
Conclusion. The efficacy of EMHPS may be related to its effect on the transcription of the genes that are involved in neurotransmission and in the showing of neuroprotective and neurotrophic effects.

Keywords: chemotranscriptomics; ethylmethylhydroxypyridine succinate; data mining; molecular pharmacology; neurons; big data. Contact: Olga Alekseevna Gromova; unesco.gromova@gmail.com

For reference: Gromova OA, Torshin IYu, Sorokin AI, et al. Chemotranscriptome analysis of the ethylmethylhydroxypyridine succinate molecule in the context of postgenomic pharmacology. Nevrologiya, neiropsikhiatriya, psikhosomatika $=$ Neurology, Neuropsychiatry, Psychosomatics. 2020;12(5):130-137. DOI: 10.14412/2074-2711-2020-5-130-137

В контексте парадигмы постгеномной медицины при оценке эффектов лекарств важно оценить воздействие лекарства на генную экспрессию (т. е. на уровни различных мPHK транскриптома) [1]. В базе данных GEO (Gene Expression Omnibus, https://www.ncbi.nlm.nih.gov/geo/) накоплены результаты более чем 160 тыс. транскриптомных исследований (свыше 50 тыс. терабайт данных). С использованием новейших методов искусственного интеллекта для анализа «сверхбольших данных» (big data) в лаборатории фармакоинформатики при Федеральном исследовательском центре «Информатика и управление» РАН был разработан метод хемотранскриптомного анализа эффектов молекул.

В настоящей работе представлены результаты хемотранскриптомного исследования дозозависимых эффектов воздействия этилметилгидроксипиридина сукцината (ЭМПГС, действующего вещества препарата Нейрокс ${ }^{\circledR}$ ) на транскрипцию 12700 аннотированных генов человека в клетках-предшественниках нейронов (клеточная линия NPC.TAK, стимуляция клеток ЭМГПС в течение 24 ч). В результате проведенного анализа установлены функциональные группы генов и конкретные гены, экспрессия которых дозозависимо и достоверно может изменяться под воздействием препарата.

Материал и методы. Результаты транскриптомных экспериментов в базе данных GEO представлены в виде таблиц. Столбцы такой таблицы соответствуют генам, а строки - воздействиям на клетку (например, добавление тех или иных веществ). В клетках таблицы содержатся значения изменений экспрессии гена при том или ином воздействии. Каждой такой «таблице транскриптомного эксперимента» соответствуют: 1) тип клеток, для которых изучались изменения экспрессии; 2) интенсивность воздействия (прежде всего, концентрации воздействующих молекул); 3) время воздействия (6 ч, 12 ч, 24 ч и т. д.). Изменения экспрессии оцениваются относительно контроля (диметилсульфоксид - ДМСО). Данные обрабатываются методами хемоинформационного анализа, основанными на комбинаторной теории разрешимости $[2,3]$. В результате получаются списки генов с достоверным повышением или снижением экспрессии, которые анализируются посредством метода функционального связывания [1] и с использованием международной номенклатуры Gene Ontology (GO).

Результаты. В результате хемотранскриптомного анализа ЭМГПС получены оценки транскрипции генома в клетках-предшественниках нейронов (линия NPC.TAK, инкубация 24 ч). Для 5627 из 12700 аннотированных генов человека установлены достоверные дозозависимые эффекты влияния ЭМГПС на транскрипцию. Существенные изменения транскрипции (изменение транскрипции более чем на $10 \%$ на 1 мкмоль ЭМГПС) были показаны для 1725 генов: экспрессия 1149 генов снизилась, а 576 генов - повысилась.

Анализ ключевых слов в аннотациях генов, экспрессия которых дозозависимо изменялась под воздействием ЭМГПС, позволил выделить термины, частоты встречаемости которых достоверно различались между группами генов с повышенной и со сниженной экспрессией (табл. 1).

Из анализа ключевых слов в аннотациях генов следует, что ЭМГПС потенциально снижает экспрессию генов, вовлеченных в ремонт ДНК, собственно транскрипцию (экспрессия) генов, деление клетки, синтез белка и процессы апоптоза. В то же время ЭМГПС повышает экспрессию генов, поддерживающих энергетический метаболизм (глюкоза, триглицериды, IGF1, кобаламин), нейротрансмиссию [ацетилхолин, инозит, серотонин, постсинаптический, ADRB2, ретина (сетчатка), одорант, KCNMA1], выживание и рост нейронов (нейриты, Akt, MAPK3, mTORC1, фрагмент ДНК теломеры 5'-TTAGGG-3').

Для установления более детальных закономерностей в функциональных группах генов, экспрессия которых дозозависимо повышалась или снижалась, был проведен системно-биологический анализ двух соответствующих списков генов. С использованием категорий международной номенклатуры GO, описывающей функции генов и соответствующих белков, было выявлено 96 категорий GO, частота встречаемости которых достоверно различается между двумя списками. Экспертный анализ, основанный на результатах анализа ключевых слов, позволил отнести каждую из этих 96 категорий к одной из девяти функциональных групп генов: «Ремонт ДНК», «Деление клеток», «Апоптоз», «Экспрессия генов», «Модуляция антивирусного иммунитета», «Синтез и метаболизм белков», «Синтез аденозинтрифосфата (АТФ)», «Нейротрансмиссия» и «Нейропротекторные, нейротрофические эффекты» (табл. 2). На рис. 1, $a$ отражены профили частот встречаемости генов этих девяти функциональных групп в зависимости от количественного изменения экспрессии (на 1 мкмоль ЭМГПС).

Анализ линейных аппроксимаций профилей частот встречаемости генов девяти функциональных групп позволяет сделать весьма важные выводы, описывающие эффект, оказываемый ЭМГПС на транскриптом в целом. Во-первых, очевидно систематическое снижение экспрессии генов из групп «Ремонт ДНК», «Деление клеток», «Апоптоз», «Экспрессия генов», «Модуляция антивирусного иммунитета», «Синтез и метаболизм белков»; лишь для отдельных генов из этих групп показано повышение экспрессии. Вовторых, экспрессия генов из групп «Нейротрансмиссия» и «Нейропротекторные, нейротрофические эффекты» систематически возрастает (см. рис. 1, в). 
Таким образом, гены, экспрессия которых дозозависимо повышается при воздействии ЭМГПС, существенно отличаются по своим биологическим функциям от генов, экспрессия которых дозозависимо повышается (на что наглядно указывают диаграммы процентных соотношений функциональных групп генов, рис. 2, см. табл. 2). На наш взгляд, установленные изменения транскрипции имеют важную физиологическую интерпретацию.

ЭМГПС снижает транскрипцию групп генов, вовлеченных в деление клетки (226 генов), собственно процесс экспрессии генов (122 гена), синтез, деградацию и секрецию белков (123 гена). Снижение экспрессии этих групп генов соответствует переходу клетки в состояние «энергосбережения» (так как все эти процессы весьма энергоемки и на их поддержание расходуется большая часть синтезируемого в клетке АТФ). Иначе говоря, ЭМГПС способствует формированию состояния «стазиса клетки», при вхождении в которое выживаемость клетки повышается за счет снижения интенсивности протекания перечисленных выше процессов.

Кроме того, ЭМГПС способствует повышению транскрипции генов, кодирующих белки, которые участвуют в нейротрансмисии (103 гена) и в осуществлении нейропротекторных и нейротрофических эффектов (49 генов). Описанные изменения в транскрипции генов способствуют повышению нейротрофического и нейропротекторного потенциала нейронов, улучшению реакции нейронов на внешние сигналы и соответствуют повышению эффективности воздействий ЭМГПС на уровне протеома и реактома (см. работы $[4,5])$. Примеры этих генов приведены в табл. 3 и более подробно рассмотрены далее; дозозависимое изменение экспрессии для этих генов приведено на рис. 2.

Обсуждение. Результаты хемотранскриптомного анализа показывают, что ЭМГПС стимулирует повышение экспрессии рецепторов различных нейротрансмиттеров: каннабиноидных, дофаминовых, серотониновых и ацетилхолиновых рецепторов. В то же время проведенный ранее хемореактомный анализ показал, что ЭМГПС может являться агонистом ацетилхо-
Таблица 1.

\author{
Ключевые слова в аннотациях генов, \\ достоверно ассоциированные \\ с вызываемыми ЭМГПС \\ изменениями экспрессии \\ (по результатам хемотранскриптомного анализа)
}

\begin{tabular}{|c|c|c|c|c|c|c|}
\hline Ключевое слово & n- & $n+$ & $\mathrm{v}-, \%$ & $\mathrm{v}+, \%$ & $v+/ v-$ & p \\
\hline Ремонт нуклеотидов & 53 & 2 & 3,79 & 0,24 & 0,06 & 0,000001 \\
\hline Нейтрофилы & 19 & 1 & 1,36 & 0,12 & 0,09 & 0,001683 \\
\hline Транскрипция & 24 & 2 & 1,71 & 0,24 & 0,14 & 0,000955 \\
\hline Протеолиз & 21 & 2 & 1,50 & 0,24 & 0,16 & 0,002649 \\
\hline Рибосома & 74 & 8 & 5,29 & 0,96 & 0,18 & 0,000001 \\
\hline ТР53 (ген белка р53) & 57 & 10 & 4,07 & 1,20 & 0,29 & 0,000038 \\
\hline Гетерохроматин & 28 & 5 & 2,00 & 0,60 & 0,30 & 0,004470 \\
\hline Ядро клетки & 119 & 24 & 8,50 & 2,87 & 0,34 & 0,000001 \\
\hline Деление клеток & 122 & 29 & 8,71 & 3,47 & 0,40 & 0,000001 \\
\hline Синтез белка & 138 & 35 & 9,86 & 4,19 & 0,43 & 0,000001 \\
\hline Репликация вирусов & 140 & 42 & 10,00 & 5,03 & 0,50 & 0,000004 \\
\hline Апоптоз & 139 & 66 & 9,93 & 7,90 & 0,80 & 0,033019 \\
\hline Глюкоза & 61 & 61 & 4,36 & 7,31 & 1,68 & 0,011473 \\
\hline Ретина (сетчатка глаза) & 27 & 29 & 1,93 & 3,47 & 1,80 & 0,049468 \\
\hline Зубы & 13 & 18 & 0,93 & 2,16 & 2,32 & 0,029647 \\
\hline Триглицериды & 10 & 15 & 0,71 & 1,80 & 2,51 & 0,031571 \\
\hline Нейриты & 9 & 14 & 0,64 & 1,68 & 2,61 & 0,031794 \\
\hline Ацетилхолин & 10 & 17 & 0,71 & 2,04 & 2,85 & 0,010697 \\
\hline Инозитол & 11 & 19 & 0,79 & 2,28 & 2,90 & 0,006254 \\
\hline MAPK3 & 5 & 9 & 0,36 & 1,08 & 3,02 & 0,053056 \\
\hline mTORC1 киназа & 7 & 13 & 0,50 & 1,56 & 3,11 & 0,017270 \\
\hline Серотонин & 2 & 6 & 0,14 & 0,72 & 5,03 & 0,037303 \\
\hline Кобаламин & 3 & 12 & 0,21 & 1,44 & 6,71 & 0,001138 \\
\hline Одорант & 2 & 9 & 0,14 & 1,08 & 7,54 & 0,003638 \\
\hline 5'-TTAGGG-3' & 1 & 5 & 0,07 & 0,60 & 8,38 & 0,026321 \\
\hline KCNMA1 & 1 & 7 & 0,07 & 0,84 & 11,74 & 0,004983 \\
\hline Akt киназа & 1 & 8 & 0,07 & 0,96 & 13,41 & 0,002179 \\
\hline ADRB2 & 1 & 9 & 0,07 & 1,08 & 15,09 & 0,000956 \\
\hline Постсинаптический & 1 & 9 & 0,07 & 1,08 & 15,09 & 0,000956 \\
\hline IGF1 & 1 & 13 & 0,07 & 1,56 & 21,80 & 0,000036 \\
\hline TORC киназы & 1 & 13 & 0,07 & 1,56 & 21,80 & 0,000036 \\
\hline
\end{tabular}

Примечания. n- и n+ - число генов, аннотированных данным ключевым словом, экспрессия которых соответственно понизилась или повысилась под воздействием ЭМГПС; v- и v+ - частоты встречаемости данного ключевого слова в аннотациях соответствующих групп генов; + + v- - отношение частот; $\mathrm{p}$ - статистическая значимость различий в частотах (критерий $\chi^{2}$ ). Ключевые слова расположены в таблице по возрастанию значений отношения $\mathrm{v}+\mathrm{v}-$. 
линовых и ГАМК-А рецепторов и практически не взаимодействует с серотониновыми, дофаминовыми и адренергическими рецепторами [5].

Сравнение результатов хемореактомного и хемотранскриптомного анализа воздействия на перечисленные рецепторы позволяет сделать три важных вывода.

Во-первых, активация ЭМГПС мускариновых рецепторов ацетилхолина усиливается воздействием ЭМГПС на повышение транскрипции генов мускариновых рецепторов.

Во-вторых, ГАМК-ергическое действие ЭМГПС может быть связано с усилением экспрессии гена рецептора нейромедина (см. далее), который также участвует в регуляции ГАМК-ергической нейротрансмиссии и активации каскадов выживания клетки (ERK1/2).

B-третьих, минимальное взаимодействие ЭМГПС с серотониновыми и дофаминовыми рецепторами на уровне протеома, наряду с усилением транскрипции генов рецепторов дофамина и серотонина (см. табл. 3) указывает на то, что ЭМГПС может усиливать действие эндогенных серотонина и дофамина без грубого вмешательства в тонкий нейротрансмиттерный баланс. Дополнительно хемотранскриптомный анализ указал на усиление ЭМГПС транскрипции гена каннабиоидного рецептора CNN1, что снижает резистентность к инсулину.

Важно отметить, что ЭМГПС стимулирует повышение экспрессии генов различных нейротрофических пептидов или их рецепторов: галанина, плейотрофина, рецептора нейропептидов В и W, рецептора нейромедина В. Галанин (ген $G A L$ ) активирует G-белок-связанные рецепторы GALR1, GALR2 и GALR3 и регулирует прием пищи, энергетический метаболизм, регенерацию нервной ткани, синтез и секрецию инсулина [6]. Галанин модулирует секрецию ацетилхолина, серотонина и норадреналина [7]. Активация рецепторов галанина имеет антиконвульсантное, антидепрессантное и успокаивающее действие. Галанин принципиально необходим для развития и функционирования нейронов, стимулируя «спраутинг» (т. е. прорастание) аксонов [8].

Таблица 2.

\begin{abstract}
Число генов различных функииональных групп, экспрессия которых снижалась или повышалась при воздействии ЭМГПС
\end{abstract}

\begin{tabular}{|lcc|}
\hline Функциональная группа генов & $\begin{array}{c}\text { Экспрессия } \\
\text { достоверно снижена }\end{array}$ & $\begin{array}{c}\text { Экспрессия } \\
\text { достоверно повышена }\end{array}$ \\
\hline Ремонт ДНК & 62 & 8 \\
\hline Деление клеток & 226 & 29 \\
\hline Апоптоз & 35 & 7 \\
\hline Экспрессия генов & 122 & 12 \\
\hline Модуляция антивирусного иммунитета & 57 & 14 \\
\hline Синтез и метаболизм белков & 123 & 29 \\
\hline Синтез АТФ & 34 & 103 \\
\hline Нейротрансмиссия & 45 & 49 \\
\hline $\begin{array}{l}\text { Нейропротекторные, } \\
\text { нейротрофические эффекты }\end{array}$ & 34 & \\
\hline
\end{tabular}

Плейотрофин (ген $P T N$ ) экспрессируется в мозге, индуцирует рост нейритов. Нейропептид плейотрофин также связывает киназу ALK, активирующую сигнальные пути MAРК, которые снижают апоптоз и стимулируют выживание нейронов [9].

Рецептор-2 нейропептидов В и W (ген NPBWR2) обнаружен на высоких уровнях в хвостатом ядре, гиппокампе и миндалине головного мозга, спинном мозге, на умеренных уровнях - в таламусе, теменной коре, гипофизе и надпочечниках. Рецептор NPBWR2 взаимодействует с опиоидами, регулирующими нейроэндокринную систему, в том числе прием пищи, память и обучение [10].

Рецептор нейромедина В (ген $N M B R$ ) опосредует свойства нейромединов - нейропептидов, характеризующихся нейролептическим и аналгезическим эффектами и регулируют допаминовую и ГАМК-нейротрансмиссию. Рецепторы нейромедина приводят к активации внутриклеточного сигнального каскада внеклеточно регулируемых киназ 1/2 (ERK1/2), вовлеченных в выживание нейронов [11].

ЭМГПС может дозозависимо повышать транскрипцию и многих других генов, способствующих выживанию нейронов. Например, белок, взаимодействующий с фактором связывания повторов теломеры (TERF2, ген TERF2IP), поддерживает длину теломер. Это белок связывается с двухцепочечными нуклеотидными повторами теломер (5'-TTAGGG-3') и снижает рекомбинацию теломер, т. е. увеличивает число возможных делений клетки. Взаимодействуя с повторами 5'-TTAGGG-3' в других сегментах генома, белок TERF2IP регулирует экспрессию генов. Отметим, что геронтоинформационный анализ ЭМГПС указал на увеличение длительности жизни модельных организмов (нематод Caenorhabditis elegans, дрозофил, мышей) [12].

Альфа-синуклеин (ген $S N C A)$ экспрессируется в основном в головном мозге (пресинаптические нервные окончания) и участвует в регуляции секреции дофамина, снижает чувствительность нейронов к различным апоптотическим стимулам, что приводит к уменьшению активации каспазы-3. Дефекты гена SNCA ассоциированы c нейродегенеративной патологией (синуклеинопатиями), болезнью Паркинсона (МIM: 168601), деменцией Леви (DLB; MIM: 127750), способствуют формированию амилоидных бляшек при болезни Альцгеймеpa [13].

Повышение экспрессии белка дифференцировки Т-клеток (ген $M A L)$ поддерживает везикулярный транспорт между комплексом Гольджи и плазматической мембраной и необходимо для биогенеза миелина.

Интересно отметить, что ЭМГПС может повышать экспрессию вкусового рецептора 2R10 (ген $T A S 2 R 10)$, который экспрессируется во вкусовых рецепторах языка и эпителия неба (густдуциновых клетках). Густдуциновый рецептор 




Рис. 1. Частоты встречаемости генов каждой из девяти функциональных групп, экспрессия которых дозозависимо изменяется при воздействии ЭМГПС (по результатам хемотранскриптомного анализа) ${ }^{l}$. a - профили частоты встречаемости генов девяти функциональных групп; б - линейные аппроксимации профилей частот; в - попарное сравнение частот встречаемости генов девяти групп

'Цветные рисунки к этой статье представлены на сайте журнала: nnp.ima-press.net 




Рис. 2. Стимулируемое ЭМГПС дозозависимое повышение экспрессии генов, вовлеченных в осуществление нейропротекторных и нейротрофических эффектов (по результатам хемотранскриптомного анализа)

TAS2R10 передает сигналы через фосфолипазу PLCB2 и кальциевый канал TRPM5, опосредуя восприятие горького вкуса [14].

Таким образом, хемотранскриптомный анализ ЭМГПС указал на характерные изменения транскрипции генов, способствующие энергосбережению, стабилизации состояния нейронов в условиях ишемии и поддерживающие нейротрофические эффекты ЭМГПС.

Что может являться физическими причинами изменений в транскриптоме, показанных для молекулы ЭМГПС? Имеются ли специальные таргетные белки ЭМГПС (предположим, те или иные факторы транскрип- ции), которые, связывая ЭМГПС, непосредственно изменяют процессы транскрипции описанных групп генов? Или же изменения транскрипции под воздействием ЭМГПС отражают изменение состояния клетки, обусловленное действием ЭМГПС на описанные ранее таргетные белки (активация мускариновых и никотиновых рецепторов ацетилхолина, активация ГАМК-А рецепторов, ингибирование ЦОГ-2 и 5-липоксигеназы, ингибирование биосинтеза простагландина $\mathrm{E}_{2}$, ингибирование фактора некроза опухоли $\alpha$, активированного фактора транскрипции NF-кB, активация рецептора $\operatorname{PPAR} \alpha$ ) [5]. Данный комплекс вопросов достаточно сложен и не может быть 
Таблица 3.

Примеры генов, вовлеченных в осуществление нейропротекторных и нейротрофических эффектов, экспрессия которых повышается при воздействии ЭМГПС (по данным хемотранскриптомного анализа)

\begin{tabular}{|c|c|c|c|}
\hline Ген & ИЭ, \% & Белок & Функция \\
\hline$N P B W R 2$ & 11,61 & $\begin{array}{c}\text { Рецептор-2 } \\
\text { нейропептидов B/W }\end{array}$ & $\begin{array}{l}\text { Рецептор нейропептидов В и W, } \\
\text { регулирующих прием пищи }\end{array}$ \\
\hline CNR1 & 16,26 & $\begin{array}{l}\text { Каннабиноидный } \\
\text { рецептор CNN1 }\end{array}$ & $\begin{array}{c}\text { Рецептор эндогенных каннабиноидов, } \\
\text { стимулирует высвобождение бета-эндорфина, } \\
\text { уменьшает возбуждающую синаптическую } \\
\text { передачу, вазодилатацию }\end{array}$ \\
\hline$G A L$ & 16,57 & $\begin{array}{l}\text { Пропептид } \\
\text { галанина }\end{array}$ & $\begin{array}{c}\text { Нейропротекторный пептид, } \\
\text { регулирует синтез гормона роста } \\
\text { и секрецию инсулина }\end{array}$ \\
\hline$D R D 2$ & 17,34 & $\begin{array}{l}\text { Рецептор дофамина } \\
\text { 2-го типа }\end{array}$ & Рецептор дофамина \\
\hline HTR4 & 17,97 & $\begin{array}{c}\text { Рецептор серотонина } \\
\text { 4-го типа }\end{array}$ & Рецептор серотонина \\
\hline$P T N$ & 18,11 & Плейотрофин & $\begin{array}{l}\text { Индуцирует рост нейритов, } \\
\text { стимулирует выживание нейронов }\end{array}$ \\
\hline$N M B R$ & 21,59 & $\begin{array}{c}\text { Рецептор } \\
\text { нейромедина В }\end{array}$ & Рецептор нейромедина \\
\hline CHRM5 & 22,02 & $\begin{array}{l}\text { Мускариновый рецептор } \\
\text { ацетилхолина, тип } 5\end{array}$ & $\begin{array}{l}\text { Рецептор ацетилхолина, стимулирует } \\
\text { переработку неорганического фосфата }\end{array}$ \\
\hline TERF2IP & 23,33 & $\begin{array}{c}\text { Белок, } \\
\text { взаимодействующий } \\
\text { с фактором TERF2 }\end{array}$ & $\begin{array}{l}\text { Поддерживает длину теломер, } \\
\text { регулирует экспрессию генов. }\end{array}$ \\
\hline$T A S 2 R 10$ & 25,75 & $\begin{array}{l}\text { Вкусовой рецептор } \\
\text { TAS2R10 }\end{array}$ & $\begin{array}{c}\text { Густдуциновый рецептор, опосредующий } \\
\text { восприятие горького вкуса }\end{array}$ \\
\hline$M A L$ & 38,32 & $\begin{array}{c}\text { Белок дифференцировки } \\
\text { Т-клеток }\end{array}$ & Необходим для биогенеза миелина \\
\hline$S N C A$ & 58,28 & Альфа-синуклеин & $\begin{array}{c}\text { Участвует в регуляции транспорта и секреции } \\
\text { дофамина, снижает чувствительность } \\
\text { нейронов к апоптотическим стимулам }\end{array}$ \\
\hline
\end{tabular}

однозначно разрешен в рамках настоящей статьи.

Заключение. В постгеномной фармакологии желательные и нежелательные эффекты лекарств рассматриваются по отношению к геному, транскриптому (возникающему в результате экспрессии генов), протеому и реактому. В настоящей работе представлены результаты хемотранскриптомного анализа молекулы ЭМГПС (препарат Нейрокс ${ }^{\circledR}$ ) с точки зрения влияния на транскрипцию генома человека в клетках линии NPC.TAK (клетки-предшественники нейронов). ЭМГПС снижает транскрипцию групп генов, вовлеченных в деление клетки (226 генов), собственно процесс экспрессии генов (122 гена), синтез, деградацию и секрецию белков (123 гена). Снижение экспрессии этих групп генов соответствует переходу клетки в состояние энергосбережения (так как все эти процессы весьма энергоемки и на их поддержание расходуется большая часть синтезируемого в клетке АТФ). Важно отметить, что ЭМГПС, действующее вещество препарата Нейрокс ${ }^{\circledR}$, может повышать транскрипцию генов, кодирующих белки, которые участвуют в нейротрансмисии (103 гена) и в осуществлении нейропротекторных и нейротрофических эффектов (49 генов). Описанные в настоящей работе изменения в транскрипции генов подготавливают нейроны к выживанию в условиях стресса, гипоксии и соответствуют повышению эффективности нейропротекторного действия ЭМГПС.

\section{Л И Т E PAT I PA/REFERENGE S}

1. Torshin IYu. Sensing the change from molecular genetics to personalized medicine. In: Bioinformatics in the Post-Genomic Era series. NY, USA: Nova Biomedical Books; 2009. ISBN 1-60692-217-0.

2. Torshin IYu, Rudakov KV. On the application of the combinatorial theory of solvability to the analysis of chemographs. Part 1: fundamentals of modern chemical bonding theory and the concept of the chemograph. Pattern Recognition and Image Analysis: Advances in Mathematical Theory and Applications. 2014;24(1):11-23.

3. Torshin IYu, Rudakov KV. Combinatorial analysis of the solvability properties of the problems of recognition and completeness of algorithmic models. Part 1: factorization approach. Pattern Recognition and Image Analysis:
Advances in Mathematical Theory and Applications. 2017;27(1):16-28.

4. Воронина ТА, Иванова ЕА. Комбинированное применение мексидола с известными лекарственными средствами.

Журнал неврологии и психиатрии им. С.С. Корсакова. 2019;119(4):115-24. doi: 10.17116/jnevro2019119041115 [Voronina TA, Ivanova EA. Combined administration of mexidol with known medicines. Zhurnal nevrologii i psikhiatrii im.

S.S. Korsakova. 2019;119(4):115-24.

doi: 10.17116/jnevro2019119041115 (In Russ.)].

5. Торшин ИЮ, Громова ОА, Сардарян ИС, Федотова ЛЭ. Сравнительный хемореактомный анализ мексидола. Журнал неврологии и психиатрии им. С.С. Корсакова. 2017;117(1-2):75-83. doi: 10.17116/jnevro20171171275-84 [Torshin IYu, Gromova OA, Sardaryan IS, Fedotova LE. A comparative chemoreactome analysis of mexidol. Zhurnal nevrologii i psikhiatrii im. S.S. Korsakova. 2017;117(1-2):75-83. doi: 10.17116/jnevro20171171275-84 (In Russ.)].

6. Guipponi M, Chentouf A, Webling KE, et al. Galanin pathogenic mutations in temporal lobe epilepsy. Hum Mol Genet. 2015 Jun 1;24(11):3082-91. doi: 10.1093/hmg/ddv060. Epub 2015 Feb 17.

7. Wynick D, Thompson SW, McMahon SB. The role of galanin as a multi-functional neuropeptide in the nervous system. Curr Opin Pharmacol. $2001 \mathrm{Feb}$;(1):73-7.

doi: 10.1016/s1471-4892(01)00006-6 
8. Suarez V, Guntinas-Lichius O, Streppel M, et al. The axotomy-induced neuropeptides galanin and pituitary adenylate cyclase-activating peptide promote axonal sprouting of primary afferent and cranial motor neurones. Eur J Neurosci. 2006;24(6):1555-64 doi: 10.1111/j.1460-9568.2006.05029.x

9. Stoica GE, Kuo A, Aigner A, et al. Identification of anaplastic lymphoma kinase as a receptor for the growth factor pleiotrophin. J Biol Chem. 2001 May 18;276(20):16772-9. doi: 10.1074/jbc.M010660200. Epub 2001 Feb 8.

10. Brezillon S, Lannoy V, Franssen JD, et al. Identification of natural ligands for the orphan
G protein-coupled receptors GPR7 and GPR8. J Biol Chem. 2003;278(2):776-83 doi: 10.1074/jbc.M206396200

11. Gendron L, Perron A, Payet MD. Low-affinity neurotensin receptor (NTS2) signaling: internalization-dependent activation of extracellular signal-regulated kinases $1 / 2$. Mol Pharmacol. 2004;66(6):1421-30. doi. $10.1124 / \mathrm{mol} .104 .002303$

12. Громова ОА, Торшин ИЮ, Федотова ЛЭ. Геронтоинформационный анализ свойств молекулы ЭМГПС. Неврология, нейропсихиатрия, психосоматика. 2017;9(4):46-54. doi: 10.14412/2074-27112017-4-46-54
[Gromova OA, Torshin IYu, Fedotova LE. Geriatric information analysis of the molecular properties of mexidole. Nevrologiya, neiropsikhiatriya, psikhosomatika = Neurology, Neuropsychiatry, Psychosomatics. 2017;9(4):46-54. doi: 10.14412/2074-2711-2017-4-46-54 (In Russ.)]. 13. Polymeropoulos MH, Lavedan C, Leroy E, et al. Mutation in the alpha-synuclein gene identified in families with Parkinson's disease. Science. 1997 Jun 27;276(5321):2045-7. doi: $10.1126 /$ science.276.5321.2045

14. Mueller KL, Hoon MA, Erlenbach I, et al. The receptors and coding logic for bitter taste. Nature. 2005 Mar 10;434(7030):225-9. doi: $10.1038 /$ nature 03352

\section{Заявление о конфликте интересов}

Исследование выполнено при поддержке грантов Российского фонда фундаментальных исследований № 18-0700944 и 19-07-00356. Конфликт интересов отсутствует. Авторы несут полную ответственность за предоставление окончательной версии рукописи в печать. Все авторы принимали участие в разработке концепции статьи и написании рукописи. Окончательная версия рукописи была одобрена всеми авторами.

Громова О.A. https://orcid.org/0000-0002-7663-710X

Торшин И.Ю. https://orcid.org/0000-0002-2659-7998

Сорокин А.И. https://orcid.org/0000-0002-6671-5012

Семенов В.A. https://orcid.org/0000-0001-8968-7459

Стаховская Л.В. https://orcid.org/0000-0001-6325-9237

\section{Conflict of Interest Statement}

The investigation has been conducted under Russian Foundation for Basic Research Grants No. 18-07-00944 and No. 19-07-00356. There are no conflicts of interest. The authors are solely responsible for submitting the final version of the manuscript for publication. All the authors have participated in developing the concept of the article and in writing the manuscript. The final version of the manuscript has been approved by all the authors. 